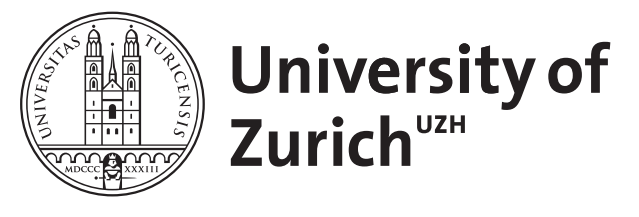

\title{
Bank bailout menus
}

Bhattacharya, S ; Nyborg, K G

\begin{abstract}
We study bailouts of banks that suffer from debt overhang problems and have private information about the quality of their assets-in-place and new investment opportunities. Menus of bailout plans are used as a screening device. Constrained optimality involves overcapitalization and nonlinear pricing, with worse types choosing larger bailouts. When investment opportunities follow the assets, we derive an equivalence result between equity injections and asset buyouts. The larger capital outlay under asset buyouts can be offset by borrowing against the assets. If investment opportunities follow the bank, equity injections offer more upside to the bailout agency. This may reduce or enhance efficiency, depending on whether screening intensity is needed mostly on assets-in-place or new investments.
\end{abstract}

DOI: https://doi.org/10.1093/rcfs/cft001

Posted at the Zurich Open Repository and Archive, University of Zurich

ZORA URL: https://doi.org/10.5167/uzh-73268

Journal Article

Accepted Version

Originally published at:

Bhattacharya, S; Nyborg, K G (2013). Bank bailout menus. Review of Corporate Finance Studies, 2(1):29-61.

DOI: https://doi.org/10.1093/rcfs/cft001 


\section{Bank Bailout Menus ${ }^{1}$}

\author{
Sudipto Bhattacharya \\ London School of Economics \\ CEPR
}

Kjell G. Nyborg

University of Zurich, Swiss Finance Institute, CEPR

November 2012

\footnotetext{
${ }^{1}$ Forthcoming, Review of Corporate Finance Studies. We thank Christopher Hennessy, the editor, for valuable discussions and comments as well as two referees and seminar participants at the Collegio Carlo Alberto, Torino; Humboldt University; London School of Economics; Norges Bank; Stanford University, UC San Diego, University of Konstanz; the 2011 SFS Finance Cavalcade; and members of the board of Finansmarkedsfondet. This research has been supported by grant 189355 of the Norwegian Research Council. We also thank NCCR-FINRISK for financial support. Nyborg thanks the Graduate School of Business, Stanford University, for hosting a research stay where this paper was completed.

Bhattacharya: Deceased. Formerly: London School of Economics, London, UK; CEPR. Nyborg: Department of Banking and Finance, University of Zürich, Plattenstrasse 14, 8032 Zürich, Switzerland; Swiss Finance Institute; CEPR. Email: kjell.nyborg@bf.uzh.ch.
} 


\section{Abstract \\ Bank Bailout Menus}

We study bailouts of banks that suffer from debt overhang problems and have private information about the quality of their assets-in-place and new investment opportunities. Menus of bailout plans are used as a screening device. Worse bank types choose larger bailouts. Constrained-optimality involves overcapitalization of banks and nonlinear pricing (e.g. the bailout agency receives proportionally more shares in larger bailouts). Equity injections and asset buyouts are equivalent when new investments follow the assets. The larger capital outlay involved in asset buyouts can be offset by borrowing against the assets. If investments follow the bank, equity injections offer more upside to the bailout agency than asset buyouts. But upside can damage as well as enhance efficiency, depending on whether screening intensity is needed mostly on assets-in-place or new investments.

Keywords: Bailouts, Equity injections, Asset buyouts, Subsidies, Debt overhang, Private information, Self-selection, Screening, Constrained-optimality.

JEL: G28, G01, D82 


\section{Introduction}

The recent spate of banking crises, arising in part from "unanticipated" declines in the quality of mortgage-backed loans and securities in US markets in particular, has brought to the fore issues of optimal mechanisms for restoring banks to well-functioning entities capable of further lending to the real sector of an economy. Banks are characterized not only by their specialized role as relationship-based lenders with hard-to-replace informational advantages vis-a-vis small and medium sized firms, they are also often funded with high leverage from dispersed creditors, be they depositors with demandable claims or (increasingly) wholesale market lenders with short-term claims which may not be refinanced. These features of bank liabilities make it extremely difficult to renegotiate their debt - to a combination of debt reduction and equity-like claims for example - directly with their creditors, and hence governments often play a direct role in ameliorating the problems arising from banks having a large degree of "debt overhang" - a surfeit of future fixed claims relative to potential future values of their extant assets in adverse scenarios.

As Myers (1977) recognized in a path-breaking paper, this gives rise to underinvestment by equityholders, or management acting in their interest, since much of any future cash flows generated by such investments could accrue to extant creditors, while the costs of investments would be borne by existing equityholders - either directly, or via a reduction in their future payoffs arising from additional promised repayments to new financiers whose claims would typically be junior to those of existing creditors. With voluntary participation, a policy of injecting funds into such banks in order to improve their incentives to invest and lend must take into account that existing equityholders have an option value that arises from the expectation of profits after repaying their creditors in the upper tail of the distributions of their future asset values.

In this paper, we investigate the properties of two often-used mechanisms for providing such cash injections to troubled banks, namely Equity Injections in return for the government acquiring a partial share of a bank's equity capital, and Asset Buyouts (or, asset buybacks) whereby the government injects cash into a bank in return for acquiring ownership of a subset, or fraction, of its (troubled) assets. We do so in a setting in which 
bank managements, who we assume to be acting in the interests of their shareholders, are privately informed about the qualities of their illiquid and risky troubled assets and new investments. As a clear consequence of such asymmetric information, fund injection mechanisms to alleviate debt overhang must be carefully designed, so as not to leave too much surplus for banks' current equityholders, relative to the status quo values of their claims in the absence of alleviating debt overhang related problems.

Not surprisingly, given the enormity of the scales of recent fund injections, or Bailouts, of especially larger banks with significant holdings of "toxic" assets, these issues have received much attention in policy-related debates as well as in the emerging academic literature. In the former sphere, policy makers have vacillated, regarding massive asset buyout programs such as TARP (Troubled Assets Relief Program) in the US, much of the budgeted resources for which were later switched to equity injections as with Citibank, for example. Bebchuk (2008) provides a summary of considerations involved in evaluating asset qualities and their likely equilibrium valuations for such buyout programs; Schaefer and Zimmermann (2009) consider a related set of issues for bank recapitalization, coupled with creation of "bad banks" to manage assets acquired by the bailout agency.

In a more detailed analytical vein, Landier and Ueda (2008), as well as Philippon and Schnabl (2011), have discussed the relative merits of some alternative bailout mechanisms that have been considered. Landier and Ueda consider an asymmetric information environment in which banks have private information about their default risks, but there is no issue of their incentives to invest in new assets. They conclude that an efficient mechanism for bailing out banks from defaulting is to provide an ex post guarantee to their creditors, to pay them the difference between the face values of their claims and what their debtor bank can repay in an adverse future state. In our context, featuring an investment disincentive problem arising from debt overhang, such a purely ex post debt guarantee would do nothing to resolve the problem. The reason is that, when a debtor bank would invest, much of any additional cash flows generated by such investment would accrue to their extant creditors in the adverse future states, and hence serve to reduce the value of any guarantee from the perspective of the bank's equityholders who would bear (directly or indirectly) the cost associated with the investment. That is the case since, by assumption, 
cash flows arising within the bank from new investments can not be distinguished - neither by their creditors, nor by their debt guarantor - from those accruing from the old assets in place.

Philippon and Schnabl (2011), on the other hand, do analyze a fully fledged debt overhang environment with asymmetric information as above, in which the resulting disincentive to invest is of concern. Another concern of theirs is opportunistic participation, whereby banks that do not need bailouts choose to participate in the program because of the financial subsidies it provides. Comparing equity injections and asset buyouts, they conclude that equity injections dominate. Their reasoning is that because equity injections allow the bailout agency to share in the upside of new investments, they reduce opportunistic program participation by banks that do not need the bailout and thus reduce the aggregate cost of the scheme. Our approach and conclusions are different.

We make use a basic insight from the screening literature that efficiency may be improved through the use of menus of contracts (e.g. Stiglitz 1975, Rothschild and Stiglitz 1976, Wilson 1977). Thus, we allow the bailout agency to offer a menu of plans, each item in the menu being tailored for a particular type (of bank quality), taking into account the incentive compatibility constraint that a bank will choose the plan that maximizes value to its extant shareholders. In contrast, Philippon and Schnabl allow the bailout agency to only offer a single contract. ${ }^{1}$ We show, with returns to assets-in-place ordered by first order stochastic dominance, that constrained-optimality can be achieved by a single plan when there are only two types. With $S \geq 2$ types, $S-1$ plans are needed. ${ }^{2}$ Constrainedoptimality involves nonlinear pricing; the larger the injection, the smaller the price per unit being sold (shares of equity or assets). Worse banks require larger injections and thus the plans involving larger injections are tailored for them. But this also means that larger injections must involve smaller prices per unit, because of participation constraints

\footnotetext{
${ }^{1}$ We also allow for more heterogeneity across banks in the returns to assets-in-place and new investments, and our menu approach means the bailout agency does not need to have full knowledge of the joint distribution of returns across types.

${ }^{2}$ By constrained-optimality here, we mean that all positive NPV investments are made (i.e., bailouts solve banks' debt overhang problems) and net subsidies to existing claimants are minimized, subject to voluntary participation.
} 
- banks' shareholders must do at least as well with a bailout as without.

We also show that a feature of constrained-optimal plans is that they require overcapitalization. This is so as to make it unattractive for better quality banks to choose the plans intended for lower quality banks. A high level of dilution at a low price per share is not a good deal for high quality banks. Types that do not need a bailout or have no positive NPV investments can be deterred from participating in the bailout scheme simply by not including plans in the menu that are favorable to them.

With respect to comparing asset buyouts and equity injections, we derive an equivalence result; namely that a constrained-optimal menu of equity injections can be replicated by a menu of asset buyouts. This holds under the assumption that new investment opportunities follow the assets. That is, a bank's future investment opportunities are reduced in proportion to the assets it sells, with the lost opportunities going to the buyer of the assets. In this scenario, there is no difference with respect to the upside from new investments the bailout agency obtains in an equity injection or an asset buyout, which also provides intuition for our equivalence result.

If investments follow the bank (interim investment opportunities are not affected by the sale of assets-in-place), equity injections offer more participation in new investments to the bailout agency than asset buyouts. We show by way of an example that this can damage as well as enhance efficiency, depending on whether screening intensity is needed mostly on assets-in-place, which favors asset buyouts, or new investments, which favors equity injections.

In general, the initial cash outlay for the bailout agency in an equity injection is smaller than in an asset buyout. Subsequent outlays relating to future investments may be equal, as in our baseline model, or, if not, can potentially be avoided by selling equity or assets before the investment is to be made. Under the belief that raising bailout funds involves social costs, for example because taxes need to be increased and/or other valuable spending gets crowded out, one may be tempted to conclude that the smaller initial outlay favors equity injections. However, the fundamental reason equity injections are smaller is that they have implicit leverage. If the bailout agency can borrow against the assets it buys in an asset buyout, it can achieve the same, relatively low need for public funds as under 
an equity injection. ${ }^{3}$ Thus, if the bailout agency can raise funds on fair terms in the market, the larger size of asset buyouts is not in and of itself a drawback. In our baseline model, where equity injections and asset buyouts result in the same level of subsidies, this observation leads us to a simple Miller-Modigliani style irrelevance result, even if there are social costs associated with using public money to bail out banks.

The rest of the paper is organized as follows. In Section 2 we set out the notation for our space of bank types, their return distributions, and two main bailout programs. The main analysis is carried out in Section 3, with general extensions considered in Section 4. Section 5 considers issues that address more specifically the optimality of equity injections versus asset buyouts. Section 6 concludes. An appendix contains all proofs that are not provided in the text.

\section{The Model}

The model addresses the problem as to how to restructure a "weak" bank's balance sheet in preparation for its return to normal banking activities, including raising fresh capital. In the absence of a bailout, a debt overhang problem prevents the bank from raising new capital. The bailout that is needed to overcome the debt overhang problem must take place ex ante, since it is assumed that there will not be sufficient time to do a bailout the instant investment (lending) opportunities arrive. The notion that the bailout process is slow while investment opportunities can be fleeting echoes Huberman (1984). ${ }^{4}$

There are three dates, $t=0,1,2$. A central agency (a government with powers of taxation) is considering bailing out banks at date 0. Banks initially have assets-in-place,

\footnotetext{
${ }^{3}$ Enhancing bailout funds through leverage is a feature of The European Financial Stability Fund (EFSF), which is authorized to borrow on the market to increase funds available for financial assistance to euro area member states (European Financial Stability Fund, European Sovereign Bond Protection Facility Launched, 17 February 2012, http://www.efsf.europa.eu/mediacentre/news/2012/2012-05-europeansovereign-bond-protection-facility-launched.htm).

${ }^{4}$ Huberman develops a model of external financing and liquidity in which there is not sufficient time to raise funds once an investment opportunity arises. It has to be raised in advance. We only assume that there is not sufficient time to do a bailout.
} 
which pay off at date 2 according to two-point distributions that depend on a bank's type. The NPV of new investment (lending) opportunities, which arrive at the interim date (time 1), also depends on a bank's type. Only a bank's management knows its type and the management's objective is to maximizes the value of existing shareholders' equity. There is universal risk neutrality and the riskfree rate is 0 .

Banks are indexed by $s \in \boldsymbol{S}=\{1, \ldots, S\}$. The assets-in-place of a bank of type $s$ either returns $H_{s}$ (state $w=H$; the "up-state"), with probability $p_{s}$, or $L_{s}<H_{s}$ (state $w=L$; the "down-state.") Thus, the date 0 full information value of the assets-in-place of a bank of type $s$ is

$$
A_{s}=p_{s} H_{s}+\left(1-p_{s}\right) L_{s}
$$

Each bank can be viewed as having separate up and down states. No assumption is made regarding any inter-dependence between different banks' up and down states. However, it is assumed that $H_{s}$ and $L_{s}$ are (weakly) increasing in $s$, while $p_{s}$ is strictly increasing. Thus, the quality of a bank is increasing in $s$, in the sense that the distribution of future returns from the assets-in-place of a bank of type $s$ first order stochastically dominates that of a bank of type $s^{\prime}<s$. Moreover, $A_{s}$ is increasing in $s$.

The interim investment costs $I$ and returns $\tilde{X}_{s}+I$ at date 2 , where $\tilde{X}_{s}$ is a random variable. Let $X_{s}=E\left[\tilde{X}_{s}\right]$, where $E[\cdot]$ is the expectations operator. Thus $X_{s}$ represents the NPV of the investment opportunity. This is also assumed to be (weakly) increasing in $s$. So banks with better assets-in-place also have better investment opportunities, perhaps reflecting managerial skill or positive synergies between assets-in-place and investment opportunities. Let $X_{s}^{\min }$ denote the greatest lower bound of the distribution of future returns from the new investment net of $I^{5}$

Banks have only two types of claims outstanding, senior debt (including deposits) and common stock. All debt matures at date 2. The promised payment, $F$, on debt is independent of bank type, which is meant as a scale normalization. We assume:

$$
\text { A1. } L_{s}+I+X_{s}^{\min } \geq F \text { for all } s
$$

\footnotetext{
${ }^{5} X_{s}^{\text {min }}$ could for example be the realization of $\tilde{X}_{s}$ in the down-state of the assets-in-place. However, we do not require $\tilde{X}_{s}$ to be contingent on the state $w_{s}$ or to have a two-point distribution.
} 
and

A2. $L_{s}<F<H_{s}$ for all $s$.

A1 says that if the interim investment is taken, creditors will be paid off in full regardless of which state occurs at date 2 . A2 says that the debt is risky without the new investment or a capital injection. It also sets up the potential for a debt overhang problem, since it implies a wealth transfer to creditors if the interim investment is made. By A1, at date 1 the expected wealth transfer is $\left(1-p_{s}\right)\left(F-L_{s}\right) .{ }^{6}$ Thus, to generate a debt overhang problem for all types, we also assume that

A3. $0<X_{s}<\left(1-p_{s}\right)\left(F-L_{s}\right)$ for all $s$.

Given A3, equityholders will not finance a positive NPV project because the transfer to creditors exceeds the NPV. This debt overhang problem motivates bailouts. ${ }^{7}$

A bailout plan is a pair of two-tuples

$$
B=((\phi, C),(\lambda, E)) \in([0,1] \times[0, \infty)) \times([0,1] \times[0, \infty))
$$

that describe an asset buyout and an equity injection, respectively. $\phi \in[0,1]$ is the fraction of assets that are bought and $C \geq 0$ is the total amount that is paid for these assets. $\lambda \in[0,1]$ is the fraction of all shares the bailout agency obtains if it injects $E \geq 0$ in fresh equity capital. After a bailout, $B$, the asset value at date 2 excluding payoffs of new investments, if any, for $w=H, L$ is

$$
w_{s}^{B}=(1-\phi) w_{s}+C+E
$$

This assumes that: (i) The stochastic rates of return on a banks' remaining assets after a partial sale remain the same as that on its assets as a whole, and (ii) all cash injections are initially invested in the riskfree asset. We also assume that (iii) interim investments follow the assets rather than the bank itself. That is, the scale of interim investments available to the bank is proportional to the assets kept on the bank's books; available new

\footnotetext{
${ }^{6} A 1$ thus allows us to capture the key idea of debt overhang that new investments involve wealth transfers to creditors in the simplest possible way.

${ }^{7}$ Bailouts could also be motivated by a desire to shore up a bank's balance sheet in order to prevent a run and the social costs that would involve. Social costs and benefits from a bailout will be considered in Section 4 , where we also relax $A 3$.
} 
investments cost $(1-\phi) I$ and return $(1-\phi)\left(\tilde{X}_{s}+I\right)$. The "lost" investment opportunity accrues to the buyer of the assets. In Section 5.2 we consider an alternative setup where a bank's investment opportunities are not reduced when assets are sold.

If the investment is not taken, the date 2 (realized) payoff to date 1 equityholders net of interim investment costs is $\max \left[w_{s}^{B}-F, 0\right]$. If it is taken, this becomes $\max \left[w_{s}^{B}+(1-\right.$ $\left.\phi)\left(\tilde{X}_{s}+I\right)-F, 0\right]-(1-\phi) I$. Let $1_{\text {invest } \mid B, s}$ be an indicator variable which is equal to 1 if the interim investment is made and 0 if not (given bailout plan $B$ and type $s$ ). We have $1_{\text {invest } \mid B, s}=1$ iff $E\left[\max \left[w_{s}^{B}+(1-\phi)\left(\tilde{X}_{s}+I\right)-F, 0\right]\right]-(1-\phi) I \geq E\left[\max \left[w_{s}^{B}-F, 0\right]\right]$,

where the expectation on the left hand side is taken over the joint distribution of $w_{s}$ and $\tilde{X}_{s}$, while on the right hand side it is taken over the marginal distribution of $w_{s}{ }^{8}$

The expected net payoff to the original shareholders of a bank of type $s$ under bailout plan $B$ is thus

$Z_{s}^{B}=(1-\lambda)\left(E\left[\max \left[w_{s}^{B}+(1-\phi)\left(\tilde{X}_{s}+I\right) 1_{\text {invest } \mid B, s}-F, 0\right]\right]-(1-\phi) I \times 1_{\text {invest } \mid B, s}\right)$.

If there is no bailout, payoffs to equity and creditors are equivalent to those under the "null plan", $B_{0} \equiv((\phi=0, C=0),(\lambda=0, E=0))$, where by $A 3$ the interim investment does not take place.

A necessary condition for the bank to accept the plan is that old shareholders are no worse off with the plan than without, that is,

$$
Z_{s}^{B} \geq Z_{s}^{B_{0}}=p_{s}\left(H_{s}-F\right)
$$

Let $\boldsymbol{B}$ be a collection, or menu, of bailout plans and let $B_{s} \in \boldsymbol{B}$ satisfy $^{9}$

$$
B_{s}=\arg \max { }_{B \in B} Z_{s}^{B}
$$

In other words, for any menu of bailout plans, the best plan for the existing shareholders of a bank of type $s$ is denoted $B_{s}$. The dependence of $B_{s}$ on a given menu, $\boldsymbol{B}$, is suppressed

\footnotetext{
${ }^{8}$ The condition for investing can also be written as $(1-\phi) X_{s}$ weakly exceeding the wealth transfer to creditors (the difference in the value of the debt with and without the investment).

${ }^{9}$ If for a given $s$ there are multiple plans that satisfy $(6), B_{s}$ can be picked arbitrarily among them.
} 
in the notation, for ease of reading. We write

$$
B_{s}=\left(\left(\phi_{s}, C_{s}\right),\left(\lambda_{s}, E_{s}\right)\right)
$$

Bailouts may involve a private loss to the agency because of the participation constraint (5) and because of a positive wealth transfer (subsidy) to creditors, as described above. The bailout agency seeks to choose a menu of bailout plans to incentivize banks to take all positive NPV investments, while minimizing its own loss. Put differently, the bailout agency's objective is to maximize social surplus while keeping as much as possible of the increase in surplus brought about by bailouts in public hands. This can be motivated for example by political pressure, or moral hazard concerns, not to reward bad past performance. It is also equivalent to saying that the bailout agency seeks to maximize its own expected profit from the bailout program, subject to banks making efficient investment decisions and voluntary participation.

More precisely, the bailout agency's objective is to choose a menu $\boldsymbol{B}$ to minimize

$$
\sum_{\boldsymbol{S}} q_{s}\{\underbrace{C_{s}-\phi_{s}\left[p_{s} H_{s}+\left(1-p_{s}\right) L_{s}+X_{s}\right]}_{\text {net subsidy from asset buyout }}+\underbrace{E_{s}-\frac{\lambda}{1-\lambda} Z_{s}^{B_{s}}}_{\text {net subsidy from equity injection }}\}
$$

subject to $(6),(5)$, and ${ }^{10}$

$$
1_{\text {invest }_{\mid B_{s}, s}}=1 \text { for all } s \text {, }
$$

and where $q_{s}$ is the prior (unconditional) probability that a bank is of type $s$. Constraint (6) means that each bank chooses the plan in the menu that maximizes the wealth of its existing shareholders. Constraint (5) means that doing so leaves the existing shareholders as least as well off as without a bailout. Constraint (9) says that under the best plan, $B_{s}$, for a bank of type $s$, debt overhang is eliminated (the interim investment is made). By $A 1$, the subsidy to creditors is fixed when the investment is taken $\left(\right.$ at $\left(1-p_{s}\right)\left(F-L_{s}\right)$ for

\footnotetext{
${ }^{10} \mathrm{By} A 3, X_{s}>0$ for all $s$. Maximization of surplus therefore implies $1_{\text {invest } \mid B_{s}, s}=1$ for all $s$. In Section 4 , we allow for the possibility that $X_{s}$ may be nonpositive. In this case, the participation constraint, (5), will change to a non-participation constraint when $X_{s} \leq 0\left(\right.$ or $\left.1_{\text {invest } \mid B_{s}, s}=0\right)$.
} 
each $s$ ) and we can write the minimization problem as

$$
\min _{\boldsymbol{B}} \sum_{\boldsymbol{S}} q_{s} Z_{s}^{B_{s}}
$$

subject to the same constraints, (6), (5), and (9).

We define a constrained-optimal menu of bailout plans to be such that the above program is solved with the participation constraint, (5), being binding. In other words, a constrained-optimal menu achieves efficient investment levels with zero windfall to equityholders. Since the subsidy to creditors is fixed when interim investments are taken, a constrained-optimal menu implements efficient investment while keeping total subsidies at the lowest theoretical possibility, given voluntary bailout participation and no expropriation of assets or claims.

\section{Analysis}

The main focus of our analysis lies in identifying constrained-optimal bailout plans. We show how to construct them and in the process establish existence results, describe the explicit form they take, and derive their key characteristics. We also compare and contrast equity injections with asset bailouts.

Define

$$
\hat{L}_{s} \equiv L_{s}+\frac{X_{s}}{1-p_{s}} \quad \text { and } \quad \hat{E}_{s} \equiv F-\hat{L}_{s}
$$

Lemma 1 Under a pure equity injection, debt overhang is eliminated if and only if $E \geq$ $\hat{E}_{s}$.

This is intuitive. It is simply a rewriting of the observation that to overcome the debt overhang problem, the capital injection from the bailout must be large enough that the NPV exceeds the expected transfer to creditors. $\hat{E}_{s}$ is thus the minimum equity injection needed for bank $s$ to make the interim investment. This is strictly decreasing in $s$, i.e., worse types need larger injections to overcome the debt overhang.

We continue with another observation, from which we can deduce an irrelevance result with respect to equity injections versus asset buyouts. 
Lemma 2 There is a one-to-one mapping with respect to payoffs to (old) equityholders between equity injection and asset buyout bailout plans. In particular, the pure equity injection plan $(\lambda, E)$ and the pure asset buyout plan $(\phi, C)$ result in the same interim investment decision and the same state-by-state payoff to (old) equityholders provided that $\phi=\lambda$ and $C=(1-\lambda) E+\lambda F$.

This has two immediate and important implications. First, the set of payoffs to old equityholders induced by a menu of equity injection plans can be replicated with a menu of asset buyout plans (and vice versa). Thus, the incentive compatibility constraints that arise from a menu of equity injections can be replicated with a menu of asset buyouts. Second, for an equity injection plan that solves the debt overhang problem for a bank of type $s$, there is a corresponding asset buyout plan that gives the same state-by-state payoffs to all claimholders and the bailout agency (and vice versa). As a corollary of these two observations, we have

Proposition 1 If there is a menu of pure equity injection plans that yields constrainedoptimality, then there is also a menu of pure asset buyout plans that does so (and vice versa). One can go from one to the other by applying the mapping in Lemma 2.

If constrained-optimality can be achieved by a menu of pure equity injection or asset buyout plans, then it can also be achieved by a menu of mixed plans (being convex combinations of the pure equity and asset buyout plans that achieve constrained-optimality). Furthermore and importantly, Lemma 2 also implies that for any mixed plan there is an equity injection plan that gives the same payoff to old equityholders. Thus, if there is a menu of mixed plans that achieve constrained-optimality, there is also a set of pure equity plans that does so. In short, in terms of finding conditions under which constrained-optimality can be achieved, it suffices to study pure equity injection plans. We have therefore chosen to cast our analysis in terms of these. However, below we also compare the characteristics of constrained-optimal equity injection plans to their corresponding constrained-optimal asset buyout plans. 


\subsection{Constrained-Optimal Menus}

Our focus is on a scenario where there can be downside heterogeneity, i.e., $L_{s}$ varies across types, but upside homogeneity, i.e.

A4. $H_{s}=H$ for all $s$.

This can be motivated by thinking of the assets held by the bank as loans, whose future values have a fixed upper bound equal to the promised repayments of the loans. Furthermore, the up-state can be thought of as representing a benign macroeconomic environment where a bank's portfolio of loans performs in an actuarially predictable manner; there is minimal uncertainty with respect to the fraction of loans that default and the corresponding writedowns, and there is a well-functioning liquid secondary market (possibly through the process of securitization) for loans that have not yet matured. The down-state can be thought of as a negatively shocked economy where asset values and market liquidity are reduced. In the down-state, default probabilities, writedowns, and the extent to which there is a secondary market for loans will thus depend to a larger extent on individual loan characteristics. In other words, a shocked economy amplifies underlying differences in the quality of loan portfolios as compared with when the economy is in a benign state. Thus, banks' private information about the characteristics of their assets (loan portfolios) matters especially when the economy is shocked. Our assumption of downside heterogeneity but upside homogeneity captures this asymmetry.

We solve for constrained-optimal menus by first finding the share-cash indifference curves that leave equityholders indifferent between a bailout and the status quo. Using Lemma 1, the indifference curve for bank $s$ is given by the locus of $\lambda$ 's and $E$ 's that satisfy

$$
p_{s}(H-F)= \begin{cases}(1-\lambda) p_{s}(H+E-F) & \text { if } E<\hat{E}_{s} \\ (1-\lambda)\left[p_{s}(H+E-F)+\left(1-p_{s}\right)\left(\hat{L}_{s}+E-F\right)\right] & \text { if } E \geq \hat{E}_{s}\end{cases}
$$

Thus, the indifference curve can be written

$$
\lambda_{s}(E)= \begin{cases}1-\frac{H-F}{H+E-F} & \text { if } E<\hat{E}_{s} \\ 1-\frac{p_{s}(H-F)}{p_{s}(H+E-F)+\left(1-p_{s}\right)\left(\hat{L}_{s}+E-F\right)} & \text { if } E \geq \hat{E}_{s} .\end{cases}
$$

The properties of these indifference curves and the way they shift as $s$ changes are key to characterizing constrained-optimal menus. An illustration is provided by Figure 1. 


\section{INSERT FIGURE 1 HERE}

Figure 1 shows the curves for two types described by $H=120, F=100, \hat{L}_{1}=80$, $\hat{L}_{2}=90, p_{1}=0.5$, and $p_{2}=2 / 3$. Observe first that the two indifference curves coincide as long as $E$ is too small to solve the debt overhang problem for either type, i.e., $E \leq \hat{E}_{2}=10$. However, as $E$ becomes larger than $\hat{E}_{2}$, the curve for the higher type $(s=2)$ moves above that for the lower type. This "uplift" arises when the equity injection is so large that equity shares in the payoff in the low state. It also reflects the additional value from the interim investment. As $E$ becomes larger than $\hat{E}_{1}$, the curve for the lower type also changes functional form. Its slope increases and exceeds that of the curve of the higher type, since an extra dollar of injections now contributes relatively more to the equity value of the lower (and less valuable) type. The greater slope of the indifference curve of the lower curve eventually allows it to cross the curve of the higher type at $(\lambda=2 / 3, E=30)$. That such an intersection point exists is intuitive as it simply means that as $E$ increases, the total contribution to equity eventually becomes larger for the less valuable type. This intersection point is unique (for $E \geq \hat{E}_{2}$ ). With a single bailout plan defined by this intersection point, debt overhang is solved for both types, and by construction of the indifference curves, the minimal level of subsidy to existing claimholders is obtained. In other words, in our example, one constrained-optimal menu simply exists of the single bailout plan, $(\lambda=2 / 3, E=30)$.

The result illustrated in Figure 1, that there is a unique plan that satisfies constrainedoptimality for $s=1,2$, is general. Define

$$
\hat{A}_{s} \equiv p_{s} H+\left(1-p_{s}\right) \hat{L}_{s}
$$

Proposition 2 Suppose a bank is one of two types, $s=1,2$, where $\hat{L}_{1}<\hat{L}_{2}, H_{s}=H$, $p_{1}<p_{2} \cdot{ }^{11}$ There is a unique pure equity injection bailout plan, $B_{E}(1,2)=\left(\lambda^{(1,2)}, E^{(1,2)}\right)$, that for both banks resolves debt overhang and achieves the minimal subsidy. The bailout plan is given by:

\footnotetext{
${ }^{11} \hat{L}_{1}<\hat{L}_{2}$ results when $L_{1} \leq L_{2}, X_{1} \leq X_{2}$, and $p_{1}<p_{2}$.
} 


$$
\lambda^{(1,2)}=\frac{(H-F)\left(p_{2}-p_{1}\right)}{p_{2} H+\left(1-p_{2}\right) \hat{L}_{2}-\left(p_{1} H+\left(1-p_{1}\right) \hat{L}_{1}\right)}=1-\frac{(H-F)\left(p_{2}-p_{1}\right)}{\hat{A}_{2}-\hat{A}_{1}}
$$

and

$$
E^{(1,2)}=F-\frac{p_{2}\left(H p_{1}+\hat{L}_{1}\left(1-p_{1}\right)\right)-p_{1}\left(H p_{2}+\hat{L}_{2}\left(1-p_{2}\right)\right)}{p_{2}-p_{1}}=F-\frac{p_{2} \hat{A}_{1}-p_{1} \hat{A}_{2}}{p_{2}-p_{1}} .
$$

Under this plan, both banks are overcapitalized: The equity injection is strictly greater than the minimum needed to overcome debt overhang fully, that is $E^{(1,2)}>\hat{E}_{1}>\hat{E}_{2}$.

The bailout plan $B_{E}(1,2)=\left(\lambda^{(1,2)}, E^{(1,2)}\right)$ represents the unique intersection point (for $\left.E \geq \hat{E}_{2}\right)$ of the two types' indifference curves, e.g., the point $(\lambda=2 / 3, E=30)$ in Figure 1. The subsidy minimizing debt relief program can also be implemented with a menu of two bailout plans, which can be chosen so as to ensure separation between the two types. Any menu $\left(\left(\lambda_{1}, E_{1}\right),\left(\lambda_{2}, E_{2}\right)\right)$ satisfying the following conditions will do: (i) $\left(\lambda_{i}, E_{i}\right)$ is on the indifference curve of type $i$; (ii) $E_{2} \in\left(\hat{E}_{2}, E^{(1,2)}\right)$; and (iii) $E_{1}>E^{(1,2)}$, where $E^{(1,2)}$ is given by (16).

The common feature of all constrained-optimal bailout menus is that the low type must be overcapitalized so as to ensure that the high type is not oversubsidized. This is evident in the example in Figure 1. Strict separation between the two types while keeping old equity to its status quo payoff implies that the plan tailored for Type 1 must be on this type's indifference curve with an $E$ to the right of the intersection point, i.e. $E_{1}>30$; while the plan tailored for Type 2 must be on this type's indifference curve with $E_{2} \in(10,30)$. In contrast, just resolving debt overhang requires injections of 20 and 10 for types 1 and 2, respectively.

When there are more than two types, we can calculate the unique intersection points, as above, for each pair. To achieve constrained-optimality, we need monotonicity of the intersection points, in the following sense:

\section{Definition 1 (Monotonicity of indifference curve intersection points)}

Suppose there are $S \geq 3$ bank types and for each type $s>1$ let $\left(\lambda^{(s-1, s)}, E^{(s-1, s)}\right)$ be the intersection point of the share-cash indifference curves of bank types $s-1$ and $s$, as defined 
by (15) and (16). ${ }^{12}$ These $S-1$ intersection points are monotonic if $E^{(s-1, s)} \leq E^{(t-1, t)}$ whenever $s>t$.

The intersection points referred to here represent the unique constrained-optimal common equity injection bailout plans for two adjacent bank types, as given in Proposition 2. Intersection point monotonicity is necessary to ensure constrained-optimality. A graphical illustration of intersection point monotonicity and its importance for constrainedoptimality is provided in Figure 2.

\section{INSERT FIGURE 2 HERE}

Figure 2 depicts the indifference curves of three types, $s=1,2,3$, with $p_{1}<p_{2}<p_{3}$, and $\hat{L}_{1}<\hat{L}_{2}<\hat{L}_{3}$. The red, blue, and green lines are the curves for types 1,2 and 3 , respectively. Focusing on the segments of these curves after they no longer coincide, we see that the green (type 3) and blue (type 2) curves intersect at a smaller $E$ than does the blue and red (type 1) curves. This is intersection point monotonicity.

As a result of intersection point monotonicity, there is also indifference curve monotonicity with respect to which type has the maximum $\lambda$ for a given equity injection. Specifically, we see in Figure 2 that for low $E$, type 3 is willing to give away a larger share of the equity than types 2 and 1 . For intermediate $E$ 's, type 2 is willing to give away a larger $\lambda$ than the other two types. And for high E's, type 1 is willing to give away a larger share. Thus, it is possible to design a menu of three bailout plans that achieves constrained-optimality by offering: (i) a plan with a low $E$ and a $\lambda$ that falls on the indifference curve of type 3; (ii) a plan with an intermediate $E$ and a $\lambda$ that falls on the indifference curve of type 2; (iii) a plan with a high $E$ and a $\lambda$ that falls on the indifference curve of type $1{ }^{13}$ Constrained-optimality can also be achieved with the two plans defined by the two intersection points (of the indifference curves of types 1 and 2 and then again of types 2 and 3). If intersection point monotonicity does not hold, such constructions are not possible and obtaining constrained-optimality would not be feasible.

\footnotetext{
${ }^{12}$ Substitute $s$ for 2 and $s-1$ for 1 in these equations.

13 "Low" $E$ means $E \in\left[\hat{E}_{3}, E^{(2,3)}\right)$; "intermediate" $E$ means $E \in\left[E^{(2,3)}, E^{(1,2)}\right)$; and "high" $E$ means $E \geq E^{(1,2)}$
} 
Theorem 1 Suppose $\hat{L}_{s}$ and $p_{s}$ are strictly increasing in $s$, and $H_{s}=H$ for all $s$. $A$ menu of equity injection plans that (a) achieves full relief of debt overhang for each bank type, $s=1, \ldots, S$ and (b) provides the equityholders of each type with an expected payoff equal to the pre-bailout level, exists if and only if the indifference curve intersection points are monotonic, which holds if and only if

$$
\frac{p_{s+1}\left(1-p_{s}\right) \hat{L}_{s}-p_{s}\left(1-p_{s+1}\right) \hat{L}_{s+1}}{p_{s}\left(1-p_{s-1}\right) \hat{L}_{s-1}-p_{s-1}\left(1-p_{s}\right) \hat{L}_{s}}>\frac{p_{s+1}-p_{s}}{p_{s}-p_{s-1}}
$$

for $s=2, \ldots, S-1$.

With more than two types, it is intuitive that the construction of a constrained-optimal menu is not possible if two or more of the types are "too close." Condition (17) makes this notion of "closeness" precise. Note that using the mapping from equity injections to equivalent asset buyouts described in Lemma 2, any optimal menu of equity injections can be replicated with a corresponding menu of asset buyouts.

We now turn to discussing the key characteristics of constrained-optimal bailout plans implied by the analysis above. We are especially interested in the pricing scheme implied by a constrained-optimal menu. Normalizing the number of initial shares to 1 , the number of new shares under a pure equity injection plan is $\lambda /(1-\lambda)$. Thus, the price per new share is $E(1-\lambda) / \lambda$. Under an asset buyout plan, the price per $100 \%$ of the assets is simply $C / \phi$.

\section{Proposition 3 (Characteristics of constrained-optimal bailouts)}

Consider constrained-optimal menus of either pure equity or pure asset buyout plans. Let $\left(\lambda_{s}, E_{s}\right)$ be the equity plan picked by type s. Let $\left(\phi_{s}, C_{s}\right)$ be the corresponding asset buyout plan (using the mapping in Lemma 2). Constrained-optimal bailout plans have the following characteristics:

1. The size of the chosen plan is decreasing in bank quality; that is, $\lambda_{s}, E_{s}, \phi_{s}$, and $C_{s}$ are all decreasing in $s$.

2. Overcapitalization: Except possibly for the highest type, banks are overcapitalized. For pure equity injections (alternatively, asset buyouts), this is to say that $E_{s}>\hat{E}_{s}$ (alternatively, $\left.C_{s}>F-\left[(1-\phi) L_{s}+X_{s} /\left(1-p_{s}\right)\right]\right)$. 
3. For pure equity injections (alternatively, asset buyouts), the price paid by the bailout agency per new share (share of the assets) is decreasing in the amount of capital injected, $E_{s}$ (alternatively, $C_{s}$ ).

4. The amount of capital injected is larger for asset buyouts than for equity injections $\left(C_{s}>E_{s}\right)$.

That both $\lambda_{s}$ and $E_{s}$ (as well as $\phi_{s}$ and $C_{s}$ ) are decreasing in $s$ follows from intersection point monotonicity. Intuitively, these results reflect that higher types need smaller injections to overcome the debt overhang problem. The nonlinear pricing structure under constrained-optimal bailout menus relates to the (piecewise) concavity of the sharecash indifference curves. Concavity is a simple implication of the fact that an additional dollar of new equity contributes a smaller and smaller share of the equity value as the equity injection increases. More fundamentally, nonlinear pricing is a direct consequence of constrained-optimality: Since lower quality banks need larger injections, larger injections will have to be associated with lower per unit prices, especially because constrainedoptimality implies that old equityholders are being kept to their status quo payoffs.

Overcapitalization is necessary so as to not oversubsidize higher types, since for an injection that injects the exact amount that eliminates debt overhang for type $s$, a bank of type $s^{\prime}>s$ would be willing to give away a larger share (as illustrated in Figure 1). A simple way to think about the result that more capital needs to be used in pure asset buyout plans than in equivalent pure equity injection plans is that it is compensation for the reduction in assets. In other words, more capital is needed to solve the debt overhang problem when assets are reduced (but see also Section 5).

Our nonlinear pricing (decreasing price per share in the size of the bailout) illustrates that any bailout plan that allows a bank to sell any quantity of assets or shares that it wishes at a fixed price (or linear pricing) - possibly subject to an upper bound is fundamentally limited, as constrained-optimality is generally not achieved under such plans. Linear pricing only works in the case of two types. ${ }^{14}$ Our analysis implies that,

\footnotetext{
${ }^{14}$ Using Figure 1 as an example, draw a straight line that is tangent to the indifference curves of both types. The two points of tangency represent separating plans. Any other construction with linear pricing
} 
in general, linear schemes either confer excessive windfalls on bailed out shareholders or result in underinvestment.

\subsection{Example}

Here, we present an example that illustrates the role of the indifference curve intersection points in constructing constrained-optimal menus of bailout plans. The example also highlights the overcapitalization and the nonlinear pricing structure that results from constrained-optimal menus.

There are three types, all with $F=100, H_{s}=120, X_{s}=5$, and $L_{s}$ and $p_{s}$ as follows:

\begin{tabular}{llll} 
Type: & $s=1$ & $s=2$ & $s=3$ \\
\hline$L_{s}$ & 70 & 73.89 & 75 \\
$p_{s}$ & 0.5 & 0.55 & $2 / 3$ \\
$\hat{L}_{s}$ & 80 & 85 & 90 \\
\hline
\end{tabular}

where $\hat{L}_{s}$ is calculated from (11).

These parameter values satisfy (17) so that indifference curve intersection point monotonicity holds. Constrained-optimal menus of bailout plans therefore exist. The intersection points of the indifference curves are as follows:

\begin{tabular}{lll} 
& $\lambda$ & $E$ \\
\hline Types 2 and 3 & 0.59 & 22.89 \\
Types 1 and 2 & 0.76 & 42.50 \\
\hline
\end{tabular}

By the analysis above, a menu consisting of these intersection-point contracts will achieve constrained-optimality. A feature of such a menu is that type 2 is, by construction, indifferent between the two plans. As discussed above, the intersection points can also be used to construct other menus consisting of three plans that strictly separate out the three types. Using the mapping in Lemma 2, equivalent pure asset buyout plans, $(\phi, C)$, are: $(0.59,68.70)$ and $(0.76,86.47)$, respectively.

is not possible. Using Figure 2, it is easy to see that this linear construction is not possible for more than two types. 
Table 1 presents expected payoffs under these bailout plans to equityholders (with and without making the interim investment) and the bailout agency (with the interim investment). It also shows the gross subsidies to equity and debt holders, which are seen to differ from the bailout agency's payoff by the NPV of 5 .

\section{INSERT TABLE 1 HERE}

The example illustrates the two key characteristics of optimal bailout plans, namely overcapitalization and nonlinear pricing. Overcapitalization can be seen from the fact that the plans inject more capital than is necessary to overcome the debt overhang problem for each type $\left(\hat{E}_{s}\right)$. The nonlinear pricing of the plans in Table 1 is illustrated in the table below. ${ }^{15}$

\section{INSERT TABLE 2 HERE}

We see that as the dilution, $\lambda$, or share of assets sold, $\phi$, increases (moving from Plan 1 to Plan 2), the price per share (equity injection) or price per $100 \%$ of the assets (asset buyout) falls. The low type prefers selling at the lower price because at the higher price the total size of the cash injection is too small. Creditors would collect too much of the aggregate date 2 payoff in the down state. The high price/low dilution plan preferred by the high type dilutes the old shares of the low type by too much.

Finally, let us compare the outcome of the two-plan menus discussed above to that of the kind of single-plan program studied by Philippon and Schnabl (2011). Specifically, consider the single-plan program that induces all three types to invest that has the lowest expected subsidy. From the geometry of the indifference curves, ${ }^{16}$ it is clear that the single equity injection plan that induces all three types to invest at the lowest expected subsidy is represented by the intersection point of types 1 and 3. In our example, this is $(\lambda=2 / 3, E=30.00)$. In comparison, for type 2 , the $\lambda$ that keeps old equityholders to the status quo payoff is 67.88 when $E=30$. Thus, the single plan essentially subsidizes type

\footnotetext{
${ }^{15}$ Recall that, normalizing the number of old shares to 1 , under a pure equity injection the number of new shares is $\lambda /(1-\lambda)$ and the price per new share is $E(1-\lambda) / \lambda$. Under an asset buyout, the price per $100 \%$ of the assets is simply $C / \phi$.

${ }^{16}$ See Figure 2 and the proof of Proposition 2.
} 
2 equityholders by 1.22 percentage points, in terms of the dilution in an equity injection. In terms of amount, the subsidy is 0.42 . This represents $8.33 \%$ of the NPV of the interim investment. In contrast, with two plans, it is possible to keep equityholders to their status quo, i.e., giving equityholders zero subsidy, as illustrated in Table 1. Across all types, the total subsidy in the example in Table 1 is 35.08. The increase in total subsidies from using the single plan is $1.19 \%$ of this. Larger differences across types will give increased oversubsidization from the single plan.

\section{Extensions}

This subsection modifies the baseline model in three respects. In the first subsection, we introduce public costs and benefits from a bailout as well as additional types that do not need or warrant a bailout. In the second subsection, we consider variable costs to raising bailout funds. The analysis focuses on equity injections. Unless otherwise specified, all assumptions of the baseline model are maintained and the parameter values are such that the monotonicity condition in Definition 1 holds.

\subsection{Additional Types and Public Costs and Benefits}

We start by introducing net public benefits of $Y_{s}$ that arise if the interim investment is made, in addition to the NPV of $X_{s}$ that accrues to the bank. This could result from, for example, a reduction in the probability of a bank run and/or incremental economy-wide NPV arising from the bank's interim lending activity. Fixed costs of administrating a bailout are netted out. Because $Y_{s}$ does not affect shareholders' payoffs or participation and incentive compatibility constraints, these public benefits do not affect the analysis above. However, the size and sign of $Y_{s}$ may affect the extent to which a bailout is desirable. $Y_{s}$ is assumed to increase in $s$.

Suppose now that some types should optimally not be bailed out because $X_{s}+Y_{s} \leq 0$. Specifically, there is a type $n$ such that $X_{s}+Y_{s} \leq 0$ if and only if $s \leq n$. Constrainedoptimality now involves types $s \leq n$ not being bailed out. Consider a pure equity injection 
menu consisting of the $S-n-1$ leftmost indifference curve intersection points (see Definition 1 and Figure 2). By construction, all plans in the menu make the shareholders of banks with type $s \leq n$ worse off. The menu thus shuts out types with $X_{s}+Y_{s} \leq 0$, as these types voluntarily choose not to get bailed out. ${ }^{17}$ Also by construction (by the same logic as in Subsection 3.1), for $s>n$, banks pick plans that induce the interim investment and leave equityholders to their status quo payoff. Hence, constrained-optimality is achieved.

Suppose next that there is no debt overhang problem for some types. Constrainedoptimality would now be achieved if these types are not bailed out, while banks facing a debt overhang problem are bailed out with minimal net subsidies as before.

Proposition 4 Suppose there is $t$ such that $X_{s} \geq\left(1-p_{s}\right)\left(F-L_{s}\right)$ for all $s>t$ and that we have monotonicity of indifference curve intersection points (according to the formulas in Definition 1). ${ }^{18}$ Suppose also that $X_{s}+Y_{s}>0$ for all $s=1, \ldots, S .{ }^{19}$ If $t>1$, constrained-optimality is achieved by a menu consisting of the $t-1$ intersection point plans $\left\{\left(\lambda^{(s-1, s)}, E^{(s-1, s)}\right)\right\}_{s=2}^{t}$ as defined in Definition 1. If $t=1$, a single-plan menu $\left\{\left(\lambda_{1}(E), E\right)\right\}$ with $E \geq E^{(1,2)}$ implements constrained-optimality.

In other words, types that do not need a bailout can be locked out by not including plans that are tailored for them. They do not take plans tailored for lower types as these dilute equity too much.

These results show that it is straightforward to deal with the possibilities that some banks do not warrant or need a bailout. Simply select the submenu (of intersectionpoint plans) that only include the plans tailored for the intermediate types that need and warrant bailouts. In particular, this means that the characteristics of constrained-optimal plans described in Proposition 3 are robust to these possibilities.

\footnotetext{
${ }^{17} X_{s}+Y_{s} \leq 0$ includes the possibility that $X_{s} \leq 0$. In this case, the bank chooses not to make the interim investment. So if $X_{s} \leq 0$, we need to set $\hat{L}_{s}=L_{s}$ and therefore also $\hat{E}_{s}=F-L_{s}$. Indifference curves are still given by (13), and the analysis is as before.

${ }^{18}$ Note that for $s>t$, the underlying curves $\lambda_{s}(E)$ that are implicit in Definition 1 no longer represent the true indifference curves of these types. Still, it is these curves that our assumption here deals with.

${ }^{19}$ This is without loss of generality, since if there are types with $X_{s}+Y_{s} \leq 0$, redefine type $s=1$ to be the smallest type with $X_{s}+Y_{s}>0$ (and allow the index $s$ to be nonpositive, to denote the cases where $\left.X_{s}+Y_{s} \leq 0\right)$.
} 


\subsection{Variable Costs to Raising Bailout Funds}

It is sometimes argued that raising bailout funds involve variable deadweight costs. Such costs might arise if the use of public funds crowds out other valuable spending. In this subsection, we examine whether such variable costs affect our result that constrainedoptimality is achieved through a separating menu. All assumptions of the baseline model are maintained. In addition, there are net benefits, excluding variable costs from raising bailout funds, of $Y_{s} \geq 0$ from making the interim investment that are increasing in $s$. Here we view $Y_{s}$ as including $X_{s}$.

Suppose therefore that there are public costs of $k E$ from raising public funds of $E$ to bail out a bank, where $k>0$ is a constant. The first issue we need to address is how to incorporate these costs into the objective function of the bailout agency. The costs from bailouts in our baseline model are subsidies to creditors and shareholders. But these are redistributions rather than direct costs. ${ }^{20}$ Thus, we face a modelling decision as to how to combine deadweight costs and subsidies. Letting $W(\boldsymbol{B})$ denote the expected payoff to the bailout agency from offering menu $\boldsymbol{B}$, we proceed by assuming that the bailout agency's objective is to

$$
\max _{\boldsymbol{B}} W(\boldsymbol{B})=\max _{\boldsymbol{B}} \sum_{\boldsymbol{S}} q_{s}\left[Y_{s} 1_{\text {invest } \mid B_{s}, s}-k E_{s}-h Q_{s}\right],
$$

where $h>0$ is a constant, and

$$
Q_{s}=E_{s}-\frac{\lambda_{s}}{1-\lambda_{s}} Z_{s}^{B_{s}}
$$

is the net subsidy to claimholders of type $s$ from bailout plan $B_{s}$, as it equals the difference between the bailout agency's capital injection and the value of the shares it gets in return. ${ }^{21}$ Maximization is subject to bank participation and incentive compatibility constraints, as before.

\footnotetext{
${ }^{20}$ The expectation of these contingent redistributions may lead to costs at some earlier, unmodelled stage.

${ }^{21}$ An alternative specification involves replacing $Q_{s}$ by $\hat{Q}_{s}$, where is $\hat{Q}_{s}=Q_{s}-\left(1-p_{s}\right)\left(F-L_{s}\right)$. That is, $\hat{Q}_{s}$ is the excess net subsidy, beyond what is given to creditors. This would not change our conclusions substantively.
} 
For simplicity, assume now that there are only two types, $s=1,2$. Bailouts are required for the interim investment to be made (by A3). We ask whether the bailout agency is better off with a separating or pooling menu. ${ }^{22}$

Consider the (separating) menu

$$
\boldsymbol{B}^{\star} \equiv\left\{B_{1}^{\star}, B_{2}^{\star}\right\} \equiv\left\{\left(\lambda_{1}^{\star}, E_{1}^{\star}\right),\left(\lambda_{2}^{\star}, E_{2}^{\star}\right)\right\} \equiv\left\{\left(\lambda^{(1,2)}, E^{(1,2)}\right),\left(\lambda_{2}\left(F-\hat{L}_{2}\right), F-\hat{L}_{2}\right)\right\}
$$

By construction, given $\boldsymbol{B}^{\star}$, type $s$ picks plan $B_{s}^{\star}$, both types invest, and net subsidies are kept to the minimum. ${ }^{23} \boldsymbol{B}^{\star}$ is the separating menu with the lowest total equity injection, among those with minimal subsidies. We assume

$A 5$. Under $\boldsymbol{B}^{\star}$, for all $s, Y_{s}$ exceeds $k E_{s}+h Q_{s}$.

Thus $\boldsymbol{B}^{\star}$ represents a separating contract where the bailout agency gains from bailing out both types.

Define $M \equiv q_{1} E_{1}^{\star}+q_{2} E_{2}^{\star}$. This is the expected equity injection under $\boldsymbol{B}^{\star}$. Expected deadweight costs are therefore $k M$.

Proposition 5 (a) If $F-\hat{L}_{1} \geq M$, the bailout agency is strictly better off with $\boldsymbol{B}^{\star}$ than any alternative one-plan menu. Suppose next that $F-\hat{L}_{1}<M$. (b) Given $h$ (and values for the other exogenous parameters), there is $\bar{k}>0$, bounded away from zero, such that $\boldsymbol{B}^{\star}$ is strictly better for the bailout agency than any one-plan menu as long as $k<\bar{k}$. (c) Given $k$ (and values for the other exogenous parameters), there is $\bar{h}$, bounded away from $\infty$, such that $\boldsymbol{B}^{\star}$ is strictly better for the bailout agency than any one-plan menu as long as $h>\bar{h}$.

For an intuition of this result, recall that under $\boldsymbol{B}^{\star}$, both types make the interim investment and subsidies are at their minimal theoretical value. Thus, to have any chance on improving on $\boldsymbol{B}^{\star}$, an alternative one-plan menu must reduce the expected equity injection, while making both types invest. ${ }^{24}$ But if $F-\hat{L}_{1} \geq M$, this is impossible. If $F-\hat{L}_{1}<M$,

\footnotetext{
${ }^{22} \mathrm{~A}$ pooling menu is a one-plan menu that both types prefer over the alternative of no bailout.

${ }^{23}$ Strictly speaking, both types are indifferent between the two plans. To generate strict preferences, modify $B_{s}^{\star}$ to be on $\lambda_{s}(E)$ arbitrarily close to $B_{s}^{\star}$ (on the right) as it is defined in (20).

${ }^{24}$ Making only type 2 invest is optimally done with just offering $B_{1}^{\star}$. But this is strictly dominated by $\boldsymbol{B}^{\star}$, by $A 5$. Making only type 1 invest is possible only with $E>E_{1}^{\star}$, which makes the bailout agency worse off than under $\boldsymbol{B}^{\star}$ conditional on either type and therefore also in expectation.
} 
a pooling plan that reduces equity injections is feasible. But since type 2's indifference curve lies above that of type 1 for $E \in\left[F-\hat{L}_{1}, M\right]$, this will necessarily increase subsidies to type 2. The saving in deadweight costs will not offset the increase in subsidies if $k$ is sufficiently small or $h$ sufficiently large. ${ }^{25}$

The proposition shows, under fairly general conditions, that separating menus that induce both types to make the interim investment dominate pooling contracts (or oneplan menus in general). While $\boldsymbol{B}^{\star}$ is not necessarily the optimal separating menu, the proposition points to the robustness of our previous result regarding the separation of types through a menu of plans that overcapitalize banks (except possibly the best type).

\section{$5 \quad$ Equity Injections versus Asset Buyouts}

Proposition 1 shows that equity injections and asset buyouts are equivalent in our baseline model, in the sense that if constrained-optimality can be achieved with a menu of pure equity injections, then it can also be achieved with a menu of pure asset buyouts, and vice versa. In this section we discuss two potential caveats to this conclusion.

\subsection{Bailout Size, Costs, and Leverage}

Since constrained-optimal equity injections are smaller than equivalent asset buyouts (Proposition 3), one might be tempted to conclude that variable costs to raising bailout funds favor equity injections over asset buyouts. In our baseline model, subsequent capital outlays are the same, given the 1-1 mapping described in Lemma 2. If the bailout agency does not sell its shares or asset holdings after the bailout, it will have to inject $\lambda I=\phi I$ of fresh capital at date 1 to fund the interim investment, either as a shareholder in the bank or as a direct holder of assets. A simple intuition for why initial equity injections are smaller is that since assets are reduced under asset buyouts, more capital needs to be injected in order to deal with the debt overhang problem. However, a more fundamental

\footnotetext{
${ }^{25}$ This basic intuition remains valid if variable deadweight costs are nonlinear, though some details of the formal argument would have to be modified.
} 
reason is that equity injections are implicitly levered; the equity that is being bought is levered. In contrast, basic asset buyouts are unlevered transactions, and, as such, require more upfront "public equity financing" than a plain equity injection.

This leads us to a standard Miller-Modigliani line of reasoning. In an asset buyout, the bailout agency can replicate the implicit leverage of an equity injection by borrowing against the assets it buys. The issue as to whether the smaller size of equity injections is an advantage therefore centers around the risk adjusted cost of borrowing to finance an asset bailout. Even if raising bailout funds through increased taxes or cutting public spending involves variable costs, if the bailout agency can borrow on fair terms, the bailout size itself is a matter of irrelevance. This conclusion regarding bailout size is not model specific. The question as to whether borrowing by the bailout agency is cheap, expensive, or fair can only be settled empirically.

\subsection{An Alternative Model of Asset Buyouts}

It has been argued by Paul Krugman ${ }^{26}$ and Philippon and Schnabl (2011), among others, that an advantage to equity injections is that the bailout agency gets to share in the NPV of new investments. But these authors do not consider the possibility of using menus to separate out different types, including types that do not need or warrant bailouts. Allowing for this, we have found that equity injections and asset buyouts may be equivalent. A caveat to this conclusion, however, is that our analysis is based on the assumption that investments follow the assets, thus giving the bailout agency a share of the upside from new investments under asset buyouts too.

Consider now a variation of our baseline model where asset buyouts provide no participation in interim investments to the bailout agency, because investment opportunities follow the bank rather than the assets. This is to say that the available investments at the interim date are not affected by the fraction $\phi$ of the assets-in-place that are transferred to the bailout agency at date 0 . So if the investment is taken, the (realized) payoff to date 1 equityholders is now $\max \left[w_{s}^{B}+\tilde{X}_{s}+I-F, 0\right]-I$. Thus, under an asset buyout, the bailout

\footnotetext{
${ }^{26}$ See, e.g., "Gordon Does Good" (op ed) by Paul Krugman, New York Times, October 13, 2008.
} 
agency has no share in the upside from new investments. We ask whether this makes asset buyouts worse than equity injections in terms of achieving constrained-optimality.

Given bailout plan $B$ and type $s$, the investment condition now becomes

$$
1_{\text {invest } \mid B, s}=1 \text { iff } E\left[\max \left[w_{s}^{B}+\tilde{X}_{s}+I-F, 0\right]\right]-I \geq E\left[\max \left[w_{s}^{B}-F, 0\right]\right]
$$

where the expectation on the left hand side is taken over the joint distribution of $w_{s}$ and $\tilde{X}_{s}$, while on the right hand side it is taken over the marginal distribution of $w_{s}$. The expected net payoff to the original shareholders of a bank of type $s$ under bailout plan $B$ in this new setup is thus

$$
Z_{s}^{B}=(1-\lambda)\left(E\left[\max \left[w_{s}^{B}+\left(\tilde{X}_{s}+I\right) 1_{\text {invest } \mid B, s}-F, 0\right]\right]-I \times 1_{\text {invest } \mid B, s}\right) .
$$

This differs from the corresponding equation, (4), in the baseline model if $\phi>0$.

We focus on pure asset buyout plans. The modified setup has no effect on the analysis of pure equity injections. Define

$$
\bar{C}_{s} \equiv F-\frac{X_{s}}{1-p_{s}}-L_{s} \frac{H-F+\frac{X_{s}}{1-p_{s}}}{H-L_{s}}=\frac{F-L_{s}-\frac{X_{s}}{1-p_{s}}}{H-L_{s}} H .
$$

Using (21) and a similar reasoning as in Section 3, we get that the indifference curve for asset buyouts is given by ${ }^{27}$

$$
\phi_{s}(C)= \begin{cases}\frac{C}{H} & \text { if } C<\bar{C}_{s} \\ \frac{\left(1-p_{s}\right)\left(L_{s}-F\right)+X_{s}+C}{A_{s}} & \text { if } C \geq \bar{C}_{s}\end{cases}
$$

As before, constrained-optimality can be achieved if and only if the intersection points of the indifference curves are monotonic. Under pure asset buyouts, the formula for the intersection point of types $s$ and $s-1$ is

$$
C^{(s-1, s)}=\frac{A_{s-1}\left[\left(1-p_{s}\right)\left(L_{s}-F\right)+X_{s}\right]-A_{s}\left[\left(1-p_{s-1}\right)\left(L_{s-1}-F\right)+X_{s-1}\right]}{A_{s}-A_{s-1}} .
$$

Intersection point monotonicity is that $C^{(s-1, s)} \leq C^{(t-1, t)}$ for $s>t$.

An example with three types is provided in Figure 3. This uses the same parameter values as in Figure 2 and Tables 1 and 2. Notice that intersection point monotonicity holds

\footnotetext{
${ }^{27}$ We sketch the derivation of $(24)$ in the appendix. For simplicity, we modify $A 1$ to $I+X{ }_{s}^{\min } \geq F$ for all $s$, in order to ensure full repayment to creditors in case the investment is taken.
} 
for the asset buyout indifference curves as they do for the equity injection ones. This is thus an example of constrained-optimality being achievable with either equity injections or asset buyouts. Even though asset buyouts involve no upside from new investments to the bailout agency, they are just as good as equity injections in this example.

\section{INSERT FIGURE 3 HERE}

However, this is not a general result. Table 3 tabulates the intersection points for equity injections and asset buyouts in three scenarios. The first scenario corresponds to Figures 2 and 3, where equity injections and asset buyouts are equivalent; intersection points are monotonic (decreasing), implying that constrained-optimality can be achieved, under either method. In the second scenario, the high type has a larger NPV from interim investments and the middle type's assets-in-place move closer to that of the high type. In this scenario, equity injections are superior to asset buyouts. So here, upside to the bailout agency is valuable. In the third scenario, the middle type's interim investment becomes as good as the high type's, but the middle type's assets-in-place moves closer to that of the low type. In this scenario, asset buyouts are superior. So here, upside to the bailout agency is damaging.

\section{INSERT TABLE 3 HERE}

To get an intuition for these results, let us focus on the middle type, since the high and low types can always be separated from each other (as illustrated in Figure 1 for equity injections). In Scenario 2, the middle type looks more like the bad type with respect to its interim investments and more like the good type with respect to its assets-in-place. Because of the high upside from new investments to the good type, this type is willing to sell its assets-in-place relatively cheaply; that is, its indifference curve shifts up (relative to Scenario 1). This makes it harder to separate out the middle type, especially because the middle type is close to the good type with respect to the value of its assets-in-place. This effect is more pronounced the more of the upside the good type can keep, which is under asset buyouts (when investments follow the bank rather than the assets). Thus, asset buyouts work less well when the middle type is close to the good type with respect 
to the value of assets-in-place and close to the bad type with respect to the NPV of interim investments. The upside from new investments to the bailout agency offered by equity injections is good in this scenario because it turns up the screening intensity on the interim investment, and this is where the biggest difference is between the middle and the high type.

Scenario 3 is the reverse situation; the middle type looks like the good type with respect to interim investments and like the bad type with respect to assets-in-place. In this case, it is helpful to turn up the screening intensity on assets-in-place, leading asset buyouts to dominate equity injections.

These examples illustrate that when investments follow the bank, there is no clear-cut choice between equity injections and asset buyouts. Upside to the bailout agency may be good in terms of achieving constrained-optimality, but it can also be damaging, depending on which element screening is needed more; assets-in-place or interim investments. This also suggests that using warrants to try to obtain more upside to the bailout agency, as suggested by Philippon and Schnabl (2011), is not necessarily optimal when one allows for screening through menus.

\section{Policy Choices and Concluding Remarks}

The main results of importance for economic policy emerging from our analysis are the following. When banks have troubled assets, having potential future values strictly below their debt cum deposit obligations, and they are heterogeneous on multiple dimensions here their probabilities of default and losses given default - it is nevertheless feasible to structure a bailout program which minimizes the implied subsidies to the equityholders of different, and privately informed, bank types, holding their payoffs at the same level as their status quo equity values in the absence of such bailouts. This can be done, under the conditions spelled out in Proposition 2 and Theorem 1 above, using separating menus of either equity injection, or asset buyout menus, which induce self-selection among heterogeneous bank types. Such optimal menus of bailout plans involve nonlinear pricing, whereby the price per share (or per unit of asset) is decreasing in the size of the bailout. 
Furthermore, quite robustly, with heterogeneous losses given default that covary positively with likelihoods of default across banks, such menus necessarily induce overcapitalization - cash injections over and above the minimal amounts needed to overcome debt overhang - at weaker banks. The extent of such overcapitalization, and thus the degree to which the bailout agency must acquire equity stakes in the bailed out banks, increases as the quality of the bank declines, in terms of both its likelihood of default and loss given default. In addition, under an equity injection based bailout plan, weaker banks are left with lower inside equity stakes for their prior shareholders. This is not the case with asset buyout based bailout plans, in which prior equity holders retain full ownership stakes in the assets remaining with the bank.

We also find that equity injections involve lower cash outlays by the bailout agency than asset buyouts. This is a result of the implicit leverage the bailout agency buys into with an equity injection. This may be of importance if there are social costs associated with raising government funding. However, if the bailout agency can borrow on fair terms in the market against the assets it takes on in an asset buyout, the initial cash outlay is not important, as such. In this case, in our baseline model where interim investment opportunities are reduced in an asset buyout, equity injections and asset buyouts are equivalent, in the sense that if it is possible to achieve constrained optimality with one method, it is possible to do so with the other one as well.

More generally, the features described above of the two types of bailout programs may impinge on policy choices over these. The lower share of inside equity under equity injections, as compared with asset buyouts, may ill serve banks' incentives to monitor the quality of their future investments, since government capital would bear some or even much of the costs of future losses arising from such lax monitoring. On the other hand, equity injections have an advantage if raising bailout funds involve a social cost. The optimal solution may depend on the interplay between the social costs, if any, of raising bailout funds and the losses, if any, arising from reduced inside holdings.

In an extension to our baseline model, where interim investment opportunities are not reduced in an asset buyout, we find that the fundamental irrelevance result in our baseline model breaks down, without the need to introduce social costs from raising bailout funds 
or agency costs. Our analysis of this alternative model indicate that equity injections do a better screening job than asset buyouts when bank types are differentiated more by the NPV of their future investment opportunities. But if banks are differentiated more by their assets-in-place, then asset buyouts may be better than equity injections. Thus, upside to the bailout agency can be damaging as well as value enhancing. In this version of our model, equity injections and asset buyouts are seen to perform different functions and the preference for one or the other bailout program, or a mixture of the two, depends on the specific circumstances of individual banks.

While we have included the possibility of public benefits to bailouts in our analysis, we have not explicitly modelled a system-wide bailout where cross-spillover effects make banks' incentive compatibility constraints dependent on the outcome for other banks. As emphasized by Gorton and Huang (2004) and more recently by Tirole (2012), this may be important in a systemic crisis. Incorporating such effects in our screening model of bank bailouts with equity injections and asset buyouts would be an interesting avenue for future research. 


\section{References}

Bebchuk, Lucien A., 2009, Buying troubled assets, Harvard law School Working Paper N. 636, April.

Gorton, Gary, and Lixin Huang, 2004, Liquidity, efficiency, and bank bailouts, American Economic Review 94, 455-483.

Huberman, Gur, 1984, External Financing and Liquidity. Journal of Finance 39, 895-908.

Landier, Augustin and Kenichi Ueda, 2009, The Economics of Bank Restructuring: Understanding the Options, International Monetary Fund, June.

Myers, Stewart C., 1977, Determinants of corporate borrowing, Journal of Financial Economics 5, 147-175.

Philippon, Thomas and Philipp Schnabl, 2011, Efficient recapitalization, Journal of Finance, forthcoming.

Rothschild, Michael and Joseph Stiglitz, 1976, Equilibrium in competitive insurance markets: An essay on the economics of imperfect information, Quarterly Journal of Economics 90, 629-649.

Schaeffer, Dorothes and Klaus F. Zimmermann, 2009, Bad Bank(s) and the recapitalization of the banking sector, Discussion Paper N. 7349, Center for Economic Policy Research, June.

Stiglitz, Joseph, 1975, The theory of "screening," education, and the distribution of income, American Economic Review 65, 283-300.

Tirole, Jean, 2012, Overcoming adverse selection: How public intervention can restore market functioning, American Economic Review 102, 29-59.

Wilson, Charles, 1977, A model of insurance markets with incomplete information, Journal of Economic Theory 16, 167-207. 


\section{Appendix: Proofs}

\section{Proof of Lemma 1}

This follows from (3), using $A 1-A 3$. Details: For an equity injection, $(\lambda, E),(3)$ becomes

$$
\begin{aligned}
& p_{s} E\left[\max \left[H_{s}+E+\tilde{X}_{s}+I-F, 0\right] \mid H_{s}\right]+\left(1-p_{s}\right) E\left[\max \left[L_{s}+E+\tilde{X}_{s}+I-F, 0\right] \mid L_{s}\right]-I \\
& \geq p_{s} \max \left[H_{s}+E-F, 0\right]+\left(1-p_{s}\right) \max \left[L_{s}+E-F, 0\right] .
\end{aligned}
$$

Using $A 1$ and $A 2$, this reduces to

$$
\begin{aligned}
& p_{s}\left[H_{s}+E-F\right]+\left(1-p_{s}\right)\left[L_{s}+E+\frac{X_{s}}{1-p_{s}}-F\right] \\
& \geq p_{s}\left[H_{s}+E-F\right]+\left(1-p_{s}\right) \max \left[L_{s}+E-F, 0\right],
\end{aligned}
$$

which, using $A 3$, is true if and only if $E \geq \hat{E}_{s}$.

\section{Proof of Lemma 2}

Let us refer to the mapping $\phi=\lambda$ and $C=(1-\lambda) E+\lambda F$ as $\mathcal{M}$. Equivalence of investment decision: By (3), under a pure equity injection, the interim investment is made if and only if (26) holds. The corresponding condition under a pure asset buyout is

$$
\begin{aligned}
& p_{s} E\left[\max \left[H_{s}(1-\phi)+C+\left(\tilde{X}_{s}+I\right)(1-\phi)-F, 0\right] \mid H_{s}\right] \\
& +\left(1-p_{s}\right) E\left[\max \left[L_{s}(1-\phi)+C+\left(\tilde{X}_{s}+I\right)(1-\phi)-F, 0\right] \mid L_{s}\right]-I(1-\phi) \\
& \geq p_{s} \max \left[H_{s}(1-\phi)+C-F, 0\right]+\left(1-p_{s}\right) \max \left[L_{s}(1-\phi)+C-F, 0\right]
\end{aligned}
$$

The mapping $\mathcal{M}$ makes all corresponding terms of (26) and (27) equivalent (to a factor of $1-\phi)$. Thus, the investment condition is equivalent. As are realized payoffs.

\section{Proof of Proposition 2}

From the expression for the indifference curve, $\lambda_{s}(E)$ for a bank of type $s$, equation (13), we see that the indifference curve changes functional form and shape as $E$ goes from representing undercapitalization, $E<\hat{E}_{s}$, to overcapitalization, $E>\hat{E}_{s}$. It is straightforward to verify that $(\mathrm{a}) \lambda_{s}(E)$ is strictly increasing and, on each region, strictly concave; (b) $\lambda_{s}^{\prime}(E)$

rises strictly as $E$ enters the overcapitalization region; and (c) $\lambda_{s}^{\prime}(E)>\frac{d}{d E} E /(H+E-F)$ for $E>\hat{E}_{s}$.

From (13), we also see that $\lambda_{1}(E)$ and $\lambda_{2}(E)$ coincide for $E \leq \hat{E}_{s}$. Thus, $\lambda_{2}(E)>\lambda_{1}(E)$ immediately to the right of $\hat{E}_{2}$, by observation (b) above. Furthermore, by observation 
(c), $\lambda_{2}(E)>\lambda_{1}(E)$ for all $E \in\left(\hat{E}_{2}, \hat{E}_{1}\right]$. To establish the proposition, we therefore need to show that $\lambda_{2}(E)$ and $\lambda_{1}(E)$ intersect once and only once for $E>\hat{E}_{1}$.

Observe now that on the overcapitalization region, $E>\hat{E}_{s}, \lambda_{s}^{\prime}(E)$ is strictly decreasing in $p_{s}$. Therefore, $\lambda_{2}(E)$ and $\lambda_{1}(E)$ can at most intersect once. Now, inspection of (13) shows that for sufficiently large $E$, we have $\lambda_{2}(E)<\lambda_{1}(E)$, since $p_{2}$ is strictly larger than $p_{1}$. Thus, since the two curves are continuous, there is a unique point of intersection. Straightforward calculations using (13) show that the two curves intersect at $E$ as given by (16), and at this point, $\lambda_{1}$ and $\lambda_{2}$ are as given by (15).

\section{Proof of Theorem 1}

The statement that constrained-optimality can be achieved if and only if monotonicity of indifference curve intersection points holds follows from preceding results and the discussion in the text (it is straightforward to formalize and extend the discussion regarding intersection monotonicity in the text to an arbitrary number $S$ of types). We need to show that indifference curve intersection point monotonicity holds if and only if (17) holds for all $s=2, \ldots, S-1$. To this end, pick any $s \in\{2, \ldots S-1\}$. Monotonicity of indifference curve intersection points implies that $E^{(s, s+1)}<E^{(s-1, s)}$, or by (16),

$$
F-\frac{p_{s} \hat{A}_{s-1}-p_{s-1} \hat{A}_{s}}{p_{s}-p_{s-1}}>F-\frac{p_{s+1} \hat{A}_{s}-p_{s} \hat{A}_{s+1}}{p_{s+1}-p_{s}} .
$$

Using $\hat{A}_{s}=p_{s} H+\left(1-p_{s}\right) \hat{L}_{s}$ (and the analogous expressions for $s-1$ and $\left.s+1\right),(28)$ simplifies to (17).

\section{Proof of Proposition 3}

Focus first on equity injections. (1) This is immediate from Proposition 2 and Theorem 1.

(2) Let $s<S$. By Theorem 1 and the associated discussion, $E_{s} \geq E^{(s-1, s)}>\hat{E}_{s}$, where the last inequality follows from Proposition 2. For $s=S$, the discussion immediately preceding Theorem 1 shows that we can have $E_{S}=\hat{E}_{S} \cdot{ }^{28}$ (3) Normalizing the number of old shares to 1 , under a pure equity injection plan, the number of new shares is $\lambda_{s} /\left(1-\lambda_{s}\right)$.

\footnotetext{
${ }^{28}$ Strictly speaking, all types are indifferent between the status quo and $(\lambda, E)=\left(\lambda_{S}\left(\hat{E}_{S}\right), \hat{E}_{S}\right)$, even though this does not solve the debt overhang problem for any other type than $s=S$. This can be dealt with by for example not including this plan in the menu, in which case the highest type will have to be overcapitalized as well.
} 
Thus, the price per new share under a pure equity injection plan is $E_{s}\left(1-\lambda_{s}\right) / \lambda_{s}$. This is decreasing in $s$ since both $\lambda_{s}$ and $E_{s}$ are decreasing in $s$. Note that (1)-(3) can be extended to pure asset buyouts by using the mapping in Lemma 2. (4) This follows directly from the mapping in Lemma 2.

\section{Proof of Proposition 4}

By Theorem 1 and the associated analysis, the offered menu implements constrainedoptimality for the subset of types that face a debt overhang problem, i.e., types $s^{\prime} \leq t$. We need to show that type $s>t$, that does not face a debt overhang problem, will not take any of the plans. Pick any $s>t$. The status quo payoff is (using an $*$ to denote the absence of a debt overhang problem)

$$
Z_{s}^{*}=p_{s}\left(H_{s}-F\right)+\left(1-p_{s}\right)\left(L_{s}+\frac{X_{s}}{1-p_{s}}-F\right)=p_{s}\left(H_{s}-F\right)+\left(1-p_{s}\right)\left(\hat{L}_{s}-F\right) .
$$

Thus, the share-cash indifference curve becomes

$$
\lambda_{s}^{*}(E)=1-\frac{p_{s}(H-F)+\left(1-p_{s}\right)\left(\hat{L}_{s}-F\right)}{p_{s}(H+E-F)+\left(1-p_{s}\right)\left(\hat{L}_{s}+E-F\right)} .
$$

A comparison with $\lambda_{s}(E)$ as given by (13) shows that $\lambda_{s}^{*}(E)<\lambda_{s}(E)$ for $E \geq F-$ $\hat{L}_{s}$. Furthermore, letting $s^{\prime} \leq t$, by the monotonicity of indifference curve intersection points, $\lambda_{s}\left(E^{\left(s^{\prime}-1, s^{\prime}\right)}\right)<\lambda^{\left(s^{\prime}-1, s^{\prime}\right)}$. Hence type $s$ would be worse off by accepting any of the intersection point plans on offer.

\section{Proof of Proposition 5}

Let $\boldsymbol{B}^{A}=\left\{\left(\lambda^{A}, E^{A}\right)\right\}$ be an alternative one-plan menu. We start by showing that $W\left(\boldsymbol{B}^{A}\right) \geq W\left(\boldsymbol{B}^{\star}\right)$ requires $E^{A} \in\left[F-\hat{L}_{1}, E_{1}^{\star}\right)$. To this end, observe first that under $\boldsymbol{B}^{\star}$ both types take the interim investment and $Y_{s}-k E_{s}^{\star}-h Q_{s}>0, s=1,2$. Furthermore, by construction, $B_{2}^{\star}$ is the constrained-optimal plan conditional on $s=2$, since $E_{2}^{\star}=F-\hat{L}_{2}$ is the smallest equity injection that induces the interim investment for a bank of type 2 , and gross subsidies are at their minimal level, $\left(1-p_{2}\right)\left(F-L_{2}\right)$. Thus, improving on $\boldsymbol{B}^{\star}$ requires reducing the equity injection taken by type 1 while inducing the interim investment. This requires

$$
E^{A} \in\left[F-\hat{L}_{1}, E_{1}^{\star}\right)
$$


which we henceforth assume.

Next, we argue that $W\left(\boldsymbol{B}^{A}\right) \geq W\left(\boldsymbol{B}^{\star}\right)$ also requires $\lambda^{A}=\lambda_{1}\left(E^{A}\right)$. Now, if $\lambda^{A}>$ $\lambda_{1}\left(E^{A}\right)$, type 1 will optimally pick no plan. This strictly reduces utility to the bailout agency relative to under $\boldsymbol{B}^{\star}$, since by assumption, $Y_{1}-k E_{1}-h Q_{1}>0$ under $B_{1}^{\star}$. (There is an additional loss of utility to the bailout agency from type 2 not being bailed out with $\left.B_{2}^{\star}\right)$. If $\lambda^{A}<\lambda_{1}\left(E^{A}\right)$, type 1 will pick $B^{A}$, but subsidies are strictly increased relative to having $\lambda^{A}=\lambda_{1}\left(E^{A}\right)$. Thus, we must have

$$
\lambda^{A}=\lambda_{1}\left(E^{A}\right)
$$

which we henceforth assume.

Offered $\boldsymbol{B}^{A}$ with (31) and (32), both types take the plan and make the interim investment. For type 1, net subsidies are the same as under $\boldsymbol{B}^{\star}$. But for type 2, net subsidies are strictly higher, since $\lambda_{2}\left(E^{A}\right)>\lambda_{1}\left(E^{A}\right)=\lambda^{A}$ for $E^{A} \in\left[F-\hat{L}_{1}, E_{1}^{\star}\right)$. Therefore, changing the menu from $\boldsymbol{B}^{\star}$ to $\boldsymbol{B}^{A}$, brings about a strict increase in expected net subsidies. At the same time, expected deadweight costs change by

$$
k\left[q_{1}\left(E^{A}-E_{2}^{\star}\right)-q_{2}\left(E_{1}^{\star}-E^{A}\right)\right]=k\left[E^{A}-M\right] .
$$

Thus, if $E^{A} \geq M$, expected deadweight costs also increase, implying that the bailout agency is worse off. Hence, if $F-\hat{L}_{1} \geq M$, the utility to the bailout agency falls regardless of $k$ or $h$. This establishes (a).

Suppose next that $F-\hat{L}_{1}<M$. Now, $W\left(\boldsymbol{B}^{A}\right) \geq W\left(\boldsymbol{B}^{\star}\right)$ requires $E^{A}<M$, which we henceforth assume. The maximum expected reduction in equity injections occurs when $E^{A}$ is at its minimum, $F-\hat{L}_{1}$, and equals

$$
G=M-\left(F-\hat{L}_{1}\right)
$$

Denote the increase in subsidy costs resulting from type 2 picking $B^{A}$ rather than $B_{2}^{\star}$ by $H\left(E^{A}\right)$. Define

$$
H=q_{2} \inf \left\{H\left(E^{A}\right) \mid E^{A} \in\left[F-\hat{L}_{1}, M\right)\right\} .
$$

Note that $H$ is bounded away from 0 since $\lambda_{2}(E)>\lambda_{1}(E)$ on $\left[F-\hat{L}_{1}, M\right]$. (b) follows by setting $\bar{k}=H / G$, since for $k<H / G$ the reduction in expected deadweight costs is less 
than the increase in expected subsidy costs. (c) follows directly from the observation that $H$ is strictly increasing in $h$ with $\lim _{h \rightarrow \infty} H=\infty$ and from the fact that $G$ is bounded.

\section{Sketch of derivation of (24).}

Under a pure asset buyout plan, $\left(\phi_{s}, C\right),(21)$ becomes

$$
\begin{aligned}
& p_{s} E\left[\max \left[H_{s}\left(1-\phi_{s}\right)+C+\tilde{X}_{s}+I-F, 0\right] \mid H_{s}\right] \\
& +\left(1-p_{s}\right) E\left[\max \left[L_{s}\left(1-\phi_{s}\right)+C+\tilde{X}_{s}+I-F, 0\right] \mid L_{s}\right]-I \\
& \geq p_{s} \max \left[H_{s}\left(1-\phi_{s}\right)+C-F, 0\right]+\left(1-p_{s}\right) \max \left[L_{s}\left(1-\phi_{s}\right)+C-F, 0\right] .
\end{aligned}
$$

Assume (which will have to be verified) that $H_{s}\left(1-\phi_{s}\right)+C-F \geq 0$. Using this, (33) reduces to

$$
L_{s}\left(1-\phi_{s}\right)+\frac{X_{s}}{1-p_{s}}+C-F \geq \max \left[L_{s}\left(1-\phi_{s}\right)+C-F, 0\right]
$$

which holds whenever $C \geq F-L_{s}\left(1-\phi_{s}\right)-X_{s} /\left(1-p_{s}\right)$. In turn, after some algebra, this yields (23) and (24). It is straightforward to verify that $H_{s}\left(1-\phi_{s}\right)+C-F \geq 0$ when $\phi_{s}$ is given by (24). 
Table 1 Examples of Constrained-Optimal Menus of Bailout Plans: Equity Injections versus Asset Buyouts

Note that $H_{s}=H=120$ for all types. The net total subsidy is the Total Subsidy less the NPV of the interim investment, $X_{s}$.

\begin{tabular}{|c|c|c|c|c|c|c|c|c|c|c|c|c|}
\hline \multirow[t]{3}{*}{ Type } & \multirow{3}{*}{$\begin{array}{c}\text { Prob } \\
\text { low }\end{array}$} & \multirow[t]{3}{*}{$L_{s}$} & \multirow[t]{3}{*}{$X_{s}$} & \multirow[t]{3}{*}{$\hat{L}_{s}$} & \multirow[t]{3}{*}{$\hat{\hat{E}_{s}}$} & \multicolumn{3}{|c|}{ Expected Payoff to Old Equity } & \multicolumn{4}{|c|}{ If Invest, Expected. . } \\
\hline & & & & & & $\overline{\text { Status }}$ & Bailout & Bailout & Subsidy & Subsidy & Subsidy & Payoff \\
\hline & & & & & & Quo & Not invest & Invest & Old Equity & Debt & Total & Bailout Ag. \\
\hline \multicolumn{13}{|c|}{ Panel A: Plan 1. Equity injection, $\lambda=0.59$ and $E=22.86$. OR Asset buyout, $\phi=0.59$ and $C=68.70}$. \\
\hline 1 (worst) & 0.5 & 70 & 5 & 80 & 20 & 10 & 8.70 & 9.28 & -0.72 & 15 & 14.28 & -9.28 \\
\hline 2 (medium) & 0.45 & 73.89 & 5 & 85 & 15 & 11 & 9.57 & 11 & 0 & 11.75 & 11.75 & -6.75 \\
\hline 3 (best) & 0.33 & 75 & 5 & 90 & 10 & 13.33 & 11.59 & 13.33 & 0 & 8.33 & 8.33 & -3.33 \\
\hline \multicolumn{13}{|c|}{ Panel B: Plan 2. Equity injection, $\lambda=0.76$ and $E=42.50$. OR Asset buyout, $\phi=0.76$ and $C=86.47$. } \\
\hline 1 (worst) & 0.5 & 70 & 5 & 80 & 20 & 10 & 8.82 & 10 & 0 & 15 & 15 & -10 \\
\hline 2 (medium) & 0.45 & 73.89 & 5 & 85 & 15 & 11 & 9.82 & 11 & 0 & 11.75 & 11.75 & -6.75 \\
\hline 3 (best) & 0.33 & 75 & 5 & 90 & 10 & 13.33 & 11.18 & 12.35 & -0.98 & 8.33 & 7.35 & -2.35 \\
\hline
\end{tabular}


Table 2 Example of Nonlinear Pricing: Equity Injections and Asset Buyouts

Plans 1 and 2 are as defined in Table 1.

\begin{tabular}{lll}
\hline & $\begin{array}{l}\text { Plan 1 } \\
\text { Small injection }\end{array}$ & Large injection \\
\hline Equity injection, Price per new share & 15.89 & 13.41 \\
Asset buyout, Price per 100\% of assets & 116.44 & 113.77 \\
Preferred by & Highest type & Lowest type \\
\hline
\end{tabular}


Table 3 Examples of Asset Buyouts versus Equity Injections when Investments Follow the Bank

The table presents the intersection points of share-cash indifference curve for pure asset buyout and pure equity injections in three scenarios. Common parameter values are: $H=120, F=100, L_{1}=70, L_{3}=75, p_{1}=0.5, p_{2}=0.67$, and $X_{1}=5$. The other parameters vary across scenarios. A method is preferred if it allows for a separating menu. The condition for this is that the intersection points are monotonically decreasing in type. For asset buyouts, the condition is: $C^{(1,2)}>C^{(2,3)}$, as calculated from $(25)$. For equity injections, the condition is: $E^{(1,2)}>E^{(2,3)}$, as calculated from (16).

\begin{tabular}{|c|c|c|c|c|c|c|c|c|}
\hline \multirow{2}{*}{$\begin{array}{l}\text { Scenario and } \\
\text { Preferred Method }\end{array}$} & \multicolumn{4}{|c|}{ Parameters } & \multicolumn{4}{|c|}{ Intersection Points } \\
\hline & $L_{2}$ & $p_{2}$ & $X_{2}$ & $X_{3}$ & $C^{(1,2)}$ & $C^{(2,3)}$ & $E^{(1,2)}$ & $E^{(2,3)}$ \\
\hline 1. Either one & 73.89 & 0.55 & 5 & 5 & 82.65 & 65.72 & 42.50 & 22.86 \\
\hline 2. Equity injection & 74.5 & 0.60 & 5 & 6 & 77.06 & 96.40 & 34.00 & 31.00 \\
\hline 3. Asset buyout & 71 & 0.60 & 6 & 6 & 87.41 & 76.90 & 32.00 & 35.00 \\
\hline
\end{tabular}




\section{Figure 1: Share-Cash Indifference Curves for Two Types}

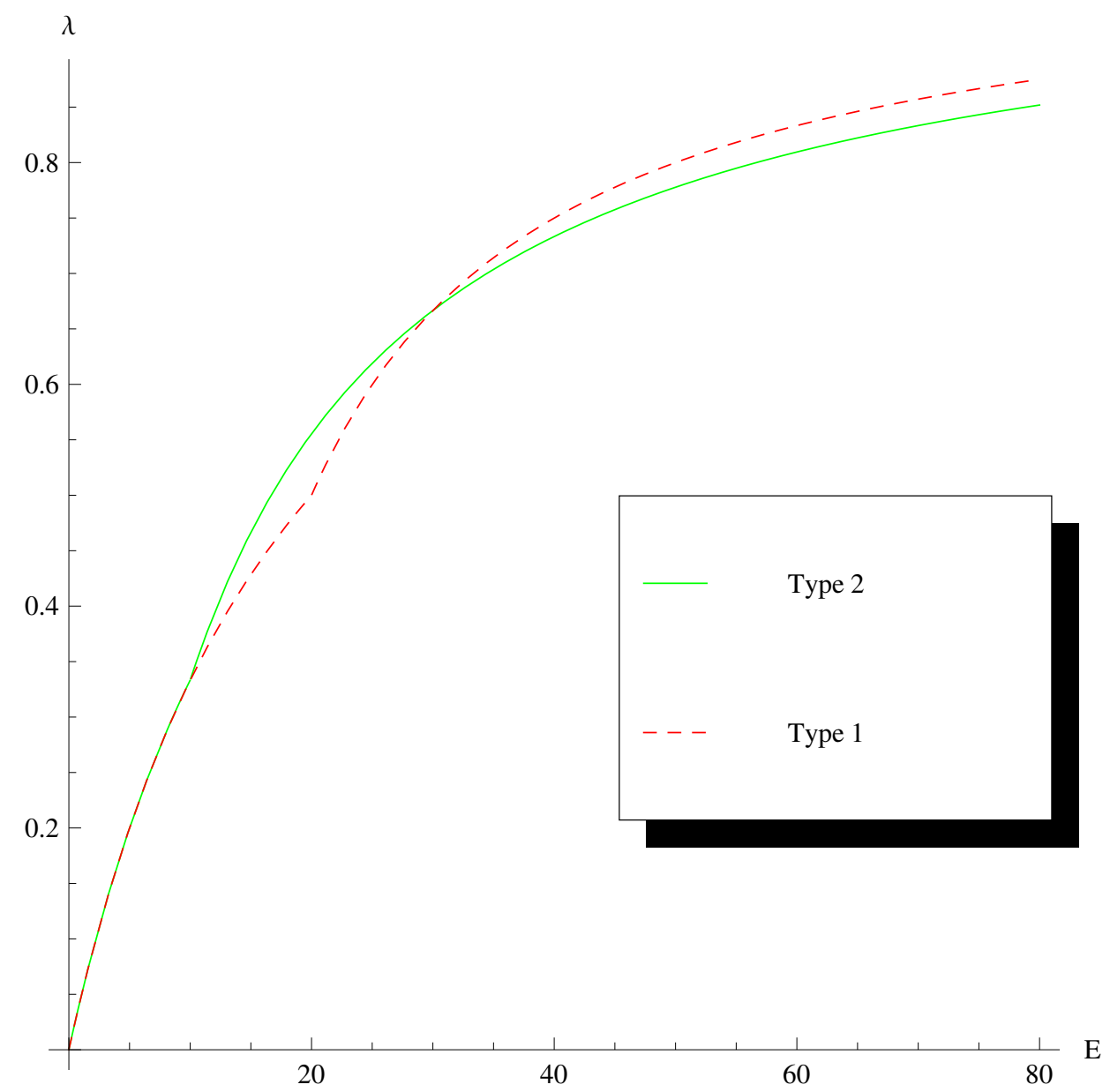

The indifference curves represent $(\lambda, E)$ combinations that keep existing equity to its status quo expected payoff. The parameter values used in the plots are as follows: $H=120, F=100, \hat{L}_{1}=80, \hat{L}_{2}=90, p_{1}=0.5$ and $p_{3}=2 / 3$. Constrained-optimality is achieved, for example, by choosing the plan represented by the intersection point $(\lambda=2 / 3, E=30)$ of the two curves. Any combination of two plans designed as follows will also work: Plan 1 - any point on Type 2's indifference curve with $10<E<30$. Plan 2 - any point on Type 1's indifference curve with $E>30$. 


\section{Figure 2: Share-Cash Indifference Curves for Three Types: \\ Constrained-Optimality Achievable}

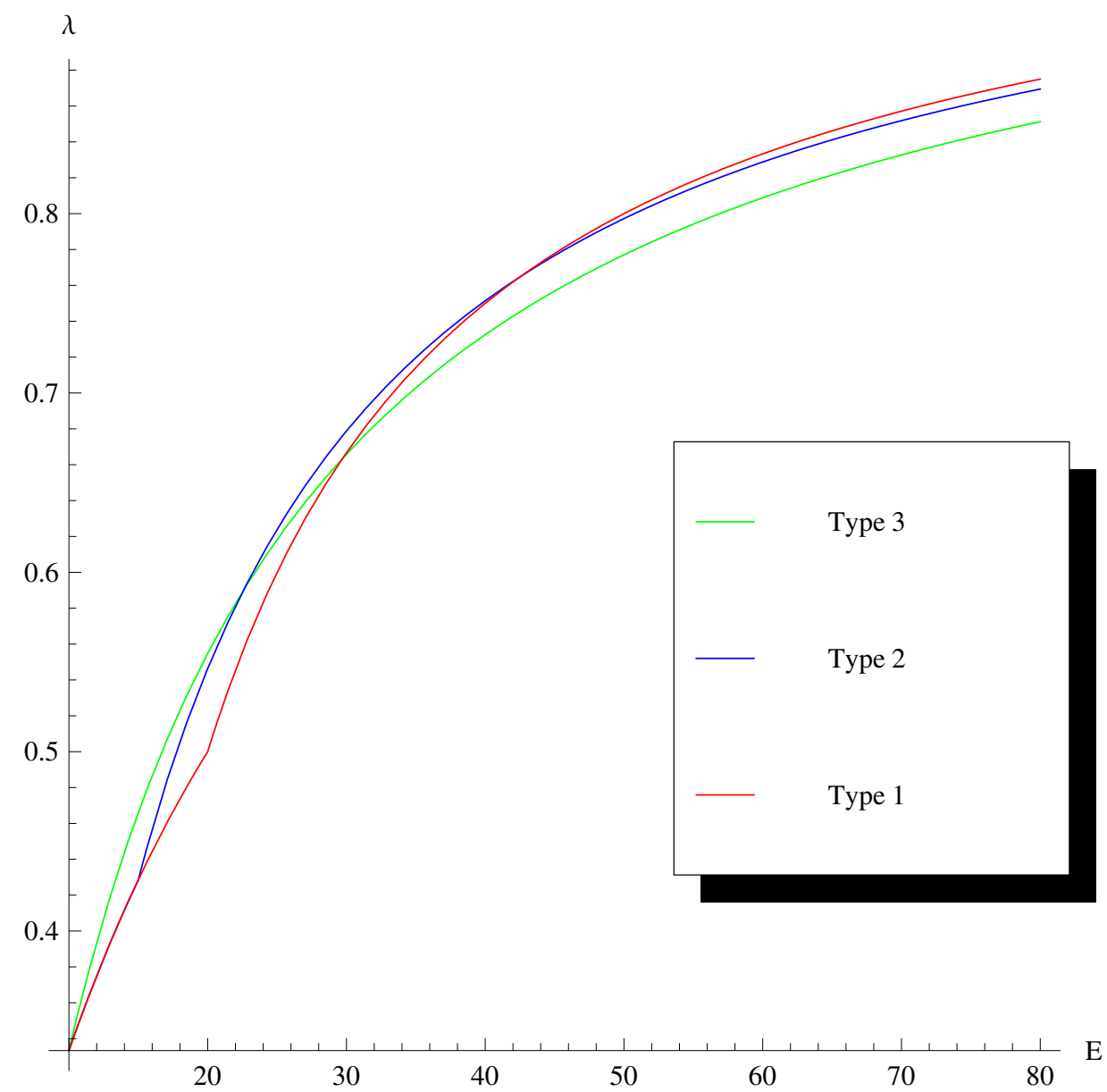

The indifference curves represent $(\lambda, E)$ combinations that keep existing equity to its status quo expected payoff. The parameter values used in the plots are as follows: $H=120, F=100, \hat{L}_{1}=80, \hat{L}_{2}=85, \hat{L}_{3}=90, p_{1}=0.5, p_{2}=0.55$, and $p_{3}=2 / 3$. Intersection point monotonicity is satisfied. The indifference curves of Types 2 and 3 intersect at $(\lambda=0.59, E=22.86)$, while the indifference curves of Types 1 and 2 intersect at $(\lambda=0.76, E=42.5)$. The curves coincide for $E \leq 10$. Constrained-optimality can be achieved, for example, by offering a menu of the two plans corresponding to these two intersection points. 
Figure 3: Indifference Curves under Asset Buyouts when Interim Investment Opportunities Follow the Bank

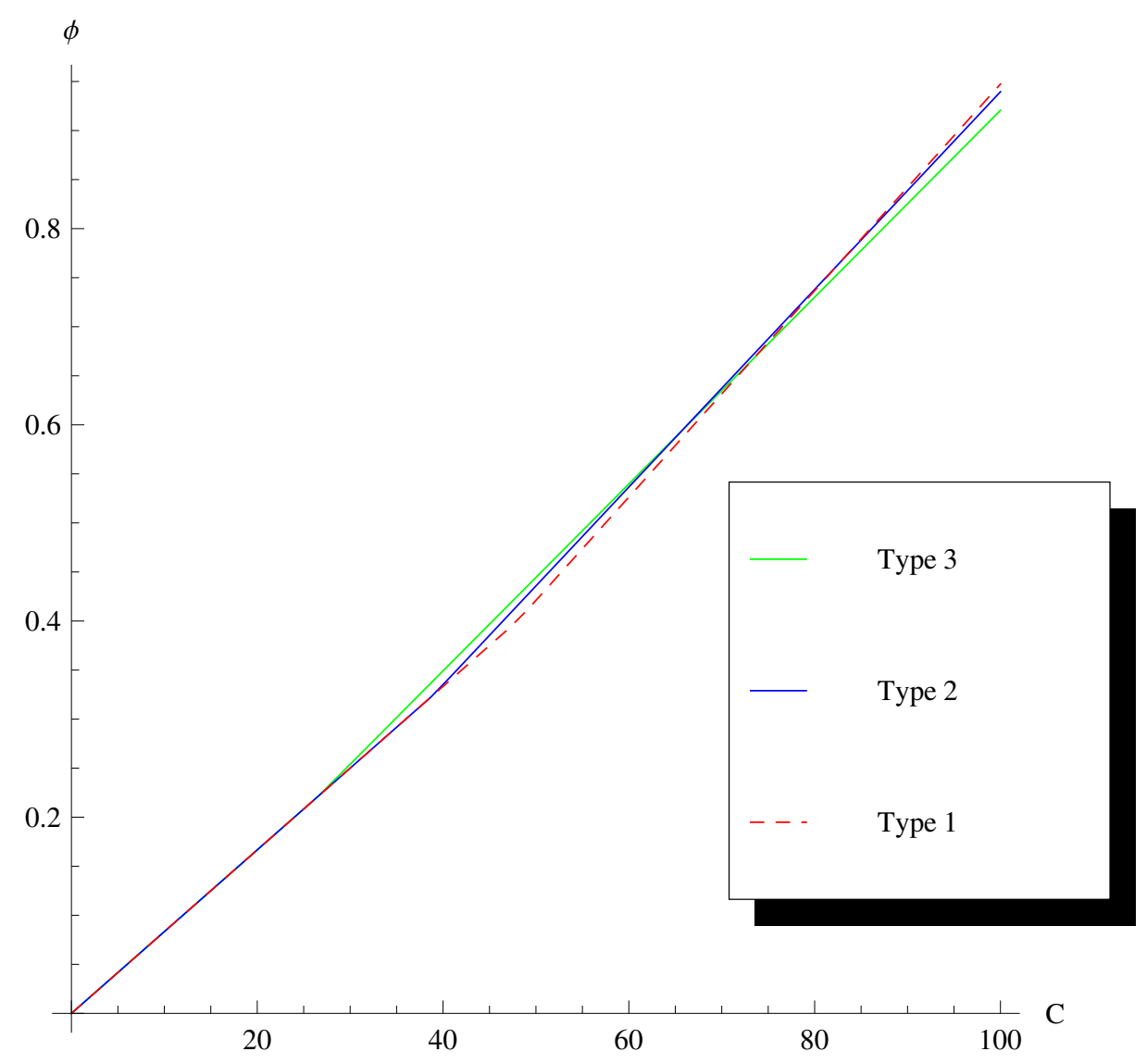

The indifference curves represent $(\phi, C)$ combinations that keep existing equity to its status quo expected payoff. The parameter values used in the plots are as follows: $H=$ $120, F=100, L_{1}=70, L_{2}=73.89, L_{3}=75, p_{1}=0.5, p_{2}=0.55, p_{3}=2 / 3$, and $X_{s}=5$ for all $s$. The indifference curves of Types 2 and 3 intersect at $(\phi=0.76, E=82.65)$, while the indifference curves of Types 1 and 2 intersect at $(\phi=0.59, E=65.72)$. Thus intersection point monotonicity is satisfied. The curves coincide for $C \leq 26.67$. Constrained-optimality can be achieved, for example, by offering a menu of the two plans corresponding to the two intersection points. 